\title{
Green Supply Chain Management Practices and Performance
}

Purpose - This study examines the deployment of pro-active and re-active practices in the implementation of Green Supply Chain Management (GSCM) and analyzes their impact on environmental, economic, and intangible performance by considering business strategy as organizational focus.

Design/methodology/approach - Data were collected from a sample of 190 ISO 14001 certified manufacturing companies in Thailand and used to test the research hypotheses. Factor analysis was used to examine the construct validity while multivariate linear regression was usedd to test criteria validity.

Findings - The threat of Legislation and regulation (re-active practices) was a consideration that resulted in companies enhancing their environmental, economic, and intangible performance. Reverse logistics practices (pro-active practices) had low levels of adoption and do not have a significantly impact on GSCM performance.

Research limitations - This study did not consider some aspects of organizational culture interaction between key customers/suppliers in the supply chain.

Practical implications -The results of this study suggest that organizations need to be aware that pursuing a low cost strategy may impact negatively on their ability to invest in GSCM.

Originality/value - This study is the first attempt to explore GSCM implementation by considering business strategy and institutional drivers in the same context.

Keywords: Green supply chain management, performance, institutional theory

Paper type: Research paper 


\section{Introduction}

Environmental concerns and the inclusion of green practices within the supply chain is a subject that has become topical in academic literature. This interest is mirrored by the increasing interest in the environment and climate change and the efforts by governments and organizations around the world to minimize their impact on the environment. According to Sarkis (2012), the integration of environmental issues and supply chain management (SCM) has become a thriving subfield over the past two decades. Despite its increasing popularity in industrialized countries, there are still several areas of green supply chain management (GSCM) that require further research particularly as greening the supply chain has been identified as a key issue of sustainable SCM (Large and Thomsen, 2011; Kenneth et al, 2012). GSCM has also begun to gain popularity in emerging economy countries such as China and Malaysia. For example, Eltayeb et al. (2011) studied the outcomes of green supply chain initiatives among ISO14001 certified firms in Malaysia, whereas Zailani et al. (2012), carried out a study on GSCM research in Malaysia to analyze the impact of internal and external forces on environmental performance. However, studies in the context of other emerging economy countries, including Thailand, are still relatively rare.

Hence, this study examines the deployment of green supply chain practices and evaluates associated outcomes. The motivation for the research is three-fold. First, although there are several studies that examine the relationships between GSCM practices and organizational performance (Eltayeb et al., 2011; Sang et al, 2012), there is a dearth of studies that have considered these relationships within the context of organizational or business strategy. Testa and Iraldo (2010) identified this gap and proposed the need to consider the impact of business strategy in the deployment of GSCM initiatives. Second, most studies (Zhu et al., 2005; De Giovanni and Vinzi, 2012; Green et al., 2012) have examined the outcomes of GSCM within the context of tangible measures such as environmental, operational, and economic performance. Consequently, research on intangible outcomes of GSCM practices is limited (Eltayeb et al., 2011). Third, as manufacturing moves to Asia, awareness of green operations or sustainability has become important but relevant studies in Asian countries are not many (Lin et al., 2011; Zhu and Sarkis, 2007; Arlbjørn and Lu“thje, 2012). In particular, within the context of South East Asia, if GSCM is to be widely implemented, links between practices and performance need to be 
identified and so there is need for more GSCM research in the sub-region (Rao, 2002; Rao and Holt, 2005).

This study also examines the deployment of GSCM and regulatory practices and analyzes their impact on environmental, economic and intangible performance using business strategy as a control variable. The dimensions of business strategy considered are low cost leadership, and quality and time-based strategy. The evaluation of intangible performance includes perception measures of both internal (employees) and external (customers and suppliers) stakeholders. This study, therefore, makes a significant contribution to on-going research that relate green practices/regulatory practices to performance outcomes by the inclusion of a different set of outcomes within the context of business strategy. Furthermore, data was collected from a developing country with an increasing global business presence but of which very little GSCM research has been carried out.

\section{Literature Review}

\subsection{Adoption of GSCM: Institutional Theory Perspective}

Several organizational theories including resource-based view, transaction cost economics, agency, network theory and institutional theory have been used to understand how companies adopt, assimilate, and develop operations strategy initiatives such as total quality management (Anderson et al, 1999), lean manufacturing (Ketokivi and Schroeder, 2004), Six Sigma (Braunscheidel et al, 2011), and supply chain management/green supply chain management (Zhu et al, 2005, Zhu et al, 2010; Lee and Cheong, 2011; Zailani et al, 2012) successfully. Within the context of GSCM, actors in the supply chain operate in a way that fulfills both customer and legal requirements. Hence, pressures from government agencies and national/international regulators will influence the adoption of environmentally responsible behavior (Delmas and Toffel 2004; Rivera 2004; Zailani et al, 2012). Narasimhan and Carter (1998) found that companies have institutionalized environmental practices because of pressure from external and internal forces as well as an awareness of the consequences of non-compliance with environmental imperatives. If companies have a legitimate concern for the environment and there is social approval, then environmental practices will be deployed more rapidly throughout the supply chain (Carter et al. 2007). There are several studies that have been carried out in developed countries that show how organizations have been driven by institutional norms to 
enhance competitive advantage by adopting environmental practices or GSCM. Zhu et al (2007) and Sarkis et al (2011) reviewed a number of studies that considered institutional theory as a key driver in adopting GSCM and found that companies were mainly influenced by external drivers. These drivers include:

(i) legislation and regulation issued by governments including, the applicability of Waste of Electronics and Electrical Equipment (WEEE) in August 2005, Kyoto Protocol's Clean Development Mechanism (CDM) in 2008 - 2012, Climate Change Act (in the UK) in 2008, American Clean Energy Bill (USA) in 2009, Restriction of Hazardous Substance (RoHS) in July 2006; and

(ii) customer requirements such as the Sustainable Packaging Program at Wal-Mart, Consumer Electronics Recycling Program at Best Buy, Zero Carbon Store Program at Tesco, Leadership in Environmental Performance at Toyota in 2004, and Go Green Dealer Program at Ford in 2010 respectively.

A research challenge identified in their study is to understand heterogeneous responses to GSCM implementation from institutional pressures exist. Therefore, this theory still needs to be studied and particularly so in emerging economy countries. Therefore, it is proposed that the institutional norms in emerging economy countries where manufacturing has been outsourced (Ferdows, 1997), will be different from results of previous studies conducted in developed countries.

\subsection{GSCM Practices}

It is important to note that the growth in adoption of green practices is, in part, due to the effect of institutional pressures driven by market and regulatory demands (Curkovic et al, 2000; Srivastava, 2007; Kumar and Putnam, 2008). According to Zhu and Sarkis (2007), economic performance remains the top priority for manufacturers and, in particular, those in developing economies. Not surprisingly, there are several studies that have attempted to link GSCM practices with organizational performance. While some studies such as Zhu and Sarkis (2004), Rao and Holt (2005) and Green et al. (2012) found positive relationships between environmental practices and organizational performance, other studies such as Giovanni and Vinzi (2012) and Huang et al. (2012) showed that there is no significant relationship between such practices and 
organizational performance. Yet other studies including Azevedo et al. (2011) and Wu and Pagell (2011) found a combination of positive and other relationships.

The evidence from the literature, therefore, is that there is a lack of consensus on the impact of GSCM on performance outcomes. This conflict was recognized and discussed in different studies including those by Eltayeb et al., (2011) and Zhu et al. (2012). Zhu et al. (2012) argued that the conflicting findings have the potential to become a barrier for organizations that intend to implement GSCM. Based on the literature examined, this study suggests three plausible sources of the inconsistency. First, the type of green supply chain practices implemented can impact performance differently (Azevedo et al., 2011). Secondly, there is a variety of performance measures in use and this variation leads to complex relationship between practices and outcomes (Zhu et al., 2012). Lastly, implementing GSCM practices in different settings can result in different performance outcomes (Koh et al., 2012).

In common with some of these findings, Murphy and Poist (2003) mentioned that there is a lack of unified framework about green practices. This lack of uniformity is clear in the literature. While some studies such as Diabat and Govindan (2011) argued that GSCM practices comprise green design, reducing energy consumption, reusing/recycling material and packaging, reverse logistics and environmental collaboration in the supply chain, others such as Wu et al. (2011) claimed that green practices include cleaner production, number of patents, internal service quality, green design, green purchasing and green innovation. Zhu et al. (2005) suggested that green practices include the sale of excess inventory, sale of scrap and used material, environmental auditing programs, commitment from senior managers and total quality environment management.

This study investigated the impact of both pro-active and re-active practices in the implementation of GSCM. These include (i) pro-active practice - green purchasing practices, eco-design practices, reverse logistics practices, and (ii) re-active practice - legislation and regulation. Also, the study separated eco-design into product-related and packaging related ecodesign practices. The study categorized green performance measures into environmental performance, economic performance, and intangible performance and included two control variables, low cost business strategy and quality/time-based business strategy - to explain the variation in performance due to a firm's strategic focus. To increase the reliability and validity 
of the survey instrument, multiple indicators were used to measure each construct. These measured items are discussed in the next section.

\subsubsection{Green Purchasing Practices}

The adoption of green purchasing is one of the commonly accepted dimensions of GSCM practice. According to Lee (2008), a buying organization with a green supply chain initiative will pay attention to green practices of their suppliers, especially the small and medium-sized enterprises. In order to ensure that suppliers meet their environmental objectives, the buying firm may deploy collaboration-based activities that include training, environmental information sharing and joint research. Other organizations may adopt a less collaborative approach by simply demanding that their suppliers adopt environmental systems such as ISO 14001. According to Heras-Saizarbitoria et al. (2011) and Vachon (2007), external motivators and particularly, customer pressure are key drivers of the adoption of ISO 14001. Other aspects of green purchasing that have been discussed in the literature include the facilitation of recycling, reuse and resource reduction (Large and Thomsen, 2011; Diabat and Givindan, 2011). There is also evidence that some organizations adopt a compliance and evaluative approach to the GSCM practices of their suppliers. This involves evaluation of suppliers based on environmental criteria and a requirement for suppliers to develop and maintain some form of environmental management system (EMS) (Sarkis, 2012; Zhu et al., 2005; Large and Thomsen, 2011, Min and Galle, 2001).

\subsubsection{Eco-Design Practices}

The importance of eco-design was identified by Buyukozkan and Cifci (2012) when they revealed that about $80 \%$ of product-related impacts on the environment can be influenced during design. Eco-design practices fall into two main categories - product-related design and packaging-related design. With respect to product design, Min and Galle (2001) suggested that cost saving opportunities at the beginning of the supply chain tend to be greater and that buying organizations need to actively seek for opportunities to utilize recycled and reused components. However, Wu et al. (2011) stressed that the environmental impacts of a product occur at all stages of its lifecycle and they identified lifecycle assessment as a commonly used attribute of GSCM. Building on the theme of lifecycle impacts, Field and Sroufe (2007) noted that one of the sources of recycled materials is post-consumer waste while Zhu et al. (2005) suggested that it 
is possible to sell or reuse products or their contents. The implication is that it is important for organizations to ensure that their products comprise contents that can be reused or recycled. This study measured product related eco-design by the proportion of the focal firm's products that contain recycled or used materials, the use of lifecycle assessment to evaluate the environmental load of products, and ensuring that recyclable or reusable contents are designed into the products.

With respect to packaging related eco-design, a discussion of GSCM practices by Zhu et al. (2005) suggested that organizations and their suppliers should collaborate to ensure that they use green packaging for their products. Other studies have identified elements of green packaging to include ensuring that packaging is reusable and recyclable (Large and Thomsen, 2011; Carter and Carter, 1998), minimizing waste by reducing packaging (Walker et al., 2008), and avoidance of hazardous material (Buyukozkan and Cifci, 2012).

\subsubsection{Reverse Logistics Practices}

Recognition of the strategic importance of reverse logistics has been described as a significant trend in GSCM and it has been shown that efficient reverse logistics networks can provide lucrative economic benefits and improve organizational competitiveness (Buyukozkan and Cifci, 2012; Murphy and Poist, 2003). Although the influence of reverse logistics on greening the supply chain is significant, development of the reverse logistics function typically lags other aspects of GSCM (Xie and Breen, 2012). Moreover, according to Lau and Wang (2009), the development of reverse logistics is at an infant stage in most developing countries although such countries are increasingly responsible for a large proportion of the world manufacturing. They further stated that most studies on reverse logistics have been carried out in developed countries. Reverse logistics practices that have been identified in previous studies include product returns and remanufacturing (Olorunniwo and $\mathrm{Li}, 2010$ ), recovery, recycling and reuse (Field and Sroufe, 2007) and redistribution (Das, 2012). These practices apply to final products, their components (Das, 2012), and packaging material (Field and Sroufe, 2007). Furthermore, from the perspective of the focal organization in a supply chain, reverse logistics activities apply to both the upstream and the downstream supply chain (Lau and Wang, 2009).

\subsubsection{Legislation and Regulatory Practices}

The involvement of governmental agencies and other regulatory bodies in GSCM is well documented in literature. Chung and Wee (2011) and Sheu (2011) noted that effective green 
regulation and incentive programs have been developed as a result of government intervention in several countries. Chen and Sheu (2009) went further to suggest that relevant public policies are central to substantiating the greening of the supply chain. Lu et al. (2007) and Hitchcock (2012) noted that legislation and regulatory practices are manifested in different ways such as PPW in 2004, WEEE and RoHS in 2003, and EUP in 2005. Lu et al. (2007) noted that many organizations are making efforts to accelerate the greening of their supply chain in response to stringent legislation and regulation. These efforts include proactively addressing environmental and social concerns in advance of regulation (Zailani et al. 2012).

\subsection{Performance Measures in Implementing GSCM Practices}

The house of sustainable SCM proposed by Teuteberg and Wittstruck (2012) identified three dimensions of performance - environmental, economic and social. The study, therefore, differed from others on GSCM performance as most of these studies focused primarily on environmental, operational and economic performance (Zhu et al., 2005; Azevedo et al. 2011; De Giovanni and Vinzi, 2012; Green et al., 2012). The importance of a social dimension to GSCM had been discussed in the literature, primarily in relation to developed economies. Eltayeb et al. (2011) argued that intangible outcomes such as company image, product image, employee satisfaction and customer loyalty or satisfaction had not received much attention as outcomes of GSCM despite studies such as Testa and Iralado (2010) and Xie and Breen (2012) asserting that GSCM can result in improved brand image, better relations with stakeholders and improved personnel motivation.

Zailani et al. (2012) measured social performance in terms of product image and company image with customers and community stakeholders. This study adopted the performance measure intangible performance based on Eltayeb et al (2011) rather than the social performance proposed by Teuteberg and Wittstruck (2012) as the socio-economic and market conditions of this study are more aligned with the former. Based on literature, this study measured intangible performance in terms of product image, customer loyalty and satisfaction and company image with suppliers, customers and employees. The study also measured economic performance in terms of reduced cost and increased profitability (Lin et al., 2011; Green et al., 2012), and environmental performance in terms of reduction in air emission, energy consumption, hazardous material, material usage and compliance to environmental standards (Zhu et al., 2012 
and 2008; Rao, 2002). While the relationship between practices and economic and environmental performance in developed economies has been extensively discussed in literature (Azevedo $e t$ al., 2011, Xie and Breen, 2012), the relationships between green practices and intangible performance, especially in developing economy countries, remains relatively unexplored.

\subsection{Business Strategy}

This study examines the intricate relationship between green practices and organizational performance within the context of the business strategy adopted by organizations. This context has not been given much attention by previous studies even though a few studies have alluded to the importance of understanding the role of business strategy. Buyukozkan and Cifci (2012) suggested that green supply chain evaluation needs to 'make sense from a business perspective' and they identified cost, quality, delivery and flexibility as key dimensions that could be considered. Testa and Iraldo (2010) also noted the importance of using environmental practices that reflect an organization's business strategy while Wu and Pagell (2010) wrote that organizations need to balance their business model and environmental issues. Several studies have examined the business strategies of organizations and their basis for competing in their respective markets. Cost, quality, reliability and flexibility have often been identified as competitive priorities for many organizations (Kathuria, 2000; Ferdows and De Meyer, 1990; Ward and Duray, 2000; Boyer and Lewis, 2002). With particular reference to Thailand, a study by Phusavat and Kanchana (2007) found that quality was the most important competitive priority for manufacturers. Delivery was also identified as an important competitive priority. Surprisingly, however, cost was not highly ranked as a competitive priority even though South East Asian countries are considered to be low-cost manufacturing countries. This study considered low cost strategy and quality and time-based strategy as relevant control variables.

\section{Research Framework and Hypotheses}

The research framework and associated hypotheses are shown in Figure 1.

\section{Insert Figure 1}


The authors believe that the implementation of GSCM practices and their potential impacts on the outcome variable may be influenced by organizational strategy. According to Min and Galle (2011), adopting GSCM practices will involve set-up costs that an organisation without significant financial resources may be unable to afford. The implication is that organizations with a low-cost focused strategy may find it difficult to adopt GSCM practices and this may impact the outcomes achieved. In addition to a cost-based strategy, organisation strategies also commonly focus on quality and time (Ward and Duray, 2000; Boyer and Lewis; 2002; Phusavat and Kanchana, 2007). This study suggests that these strategies may also impact on the adoption of GSCM practices and their outcomes since such practices cannot be removed from the overall strategic direction of the organization. The following set of hypotheses argue that a firm's business strategy is significantly associated with environmental, economic and intangible performance. For example, a low-cost strategy precludes a firm from investing heavily in environment improvement, so the relationship should be negatively related. It is therefore proposed that:

$H_{1}$ : A low-cost business strategy is inversely associated with environmental performance.

$\mathrm{H}_{2}$ : A low-cost business strategy is inversely associated with economic performance.

$H_{3}$ : A low-cost business strategy is inversely associated with intangible performance.

$H_{4}$ : A quality and time-based business strategy is positively associated with environmental performance.

$H_{5}$ : A quality and time-based business strategy is positively associated with economic performance.

$H_{6}$ : A quality and time-based business strategy is positively associated with intangible performance.

The use of performance outcomes to evaluate GSCM initiatives has been acknowledged in previous studies (Zhu et al., 2005; Azevedo et al. 2011; Green et al., 2012). According to Buyukozkan and Cifci (2012), it is important to use environmental and non-environmental-based measures to evaluate green supply chains. This is because in addition to enabling the greening of the supply chain, the initiative needs to be sensible when viewed from a business perspective. The potential impacts of different GSCM practices have also been discussed in literature. 
According to Kumar et al. (2012), GSCM practices provide the potential for cost savings, improved efficiency and attracting new suppliers and customers. They further explained that specific reasons for adopting GSCM practices included improved brand reputation, compensating for global warming and increasing energy and commodity prices as well as improved supply chain integration. On the basis of this and of the earlier discussion on performance measures in the literature section, the hypotheses in this study are based on three environmental and non-environmental outcomes.

This study aims to examine whether different green supply chain practices can impact on all three dimensions of outcomes that have been identified. For example, according to Koh et al (2012), eco-product design implies effective use of materials and waste reduction. Reduction of waste can lead to better costs for the organisation and better use of materials can positively impact environmental performance while eco-designed products can lead to improved brand image. A similar argument applies to eco-packaging design which is typified by reusable and recyclable packaging, waste minimization by means of reduced packaging and reduction or elimination of hazardous material in packaging (Carter and Carter, 1998; Walker et al., 2008; Large and Thomsen, 2011; Buyukozkan and Cifci, 2012). Similarly, regulatory practices typically involve the reduction or elimination of hazardous materials in products and packaging and well as the adoption of recycling, reuse and environmentally-friendly disposal ( $\mathrm{Lu}$ et al., 2007; Hitchcock, 2012) and these can all impact cost, company/brand image and the environment. The following set of hypotheses argue that GSCM practices significantly predict the level of environmental, economic and intangible performance of a firm. It is, therefore, proposed that:

$H_{7}$ : Green purchasing has a positive impact on environmental performance.

$H_{8}$ : Product-related eco-design has a positive impact on environmental performance.

H9: Packaging-related eco-design has a positive impact on environmental performance.

$H_{10}$ : Reverse logistics has a positive impact on environmental performance.

$H_{11}$ : Legislation and regulation have a positive impact on environmental performance.

$H_{12}$ : Green purchasing has a positive impact on economic performance. 
$H_{13}$ : Product-related eco-design has a positive impact on economic performance.

$H_{14}$ : Packaging-related eco-design has a positive impact on economic performance.

$H_{15}$ : Reverse logistics has a positive impact on economic performance.

$H_{16}$ : Legislation and regulation have a positively impact on economic performance.

$H_{17}$ : Green purchasing has a positive impact on intangible performance.

$H_{18}$ : Product-related eco-design has a positive impact on intangible performance.

$H_{19}$ : Packaging-related eco-design has a positive impact on intangible performance.

$H_{20}$ : Reverse logistics has a positive impact on intangible performance.

$H_{21}$ : Legislation and regulation have a positive impact on intangible performance.

\section{Research Design, Analyses and Results}

\subsection{Research Instrument Design}

The survey instrument was adapted from Zailani et al. (2012). In the original survey instrument used in Zailani et al. (2012), the authors noted that there were few large-scale studies in the area of eco-design, its drivers and effect on environmental outcomes. Hence, they included the few available measures and constructed new items in their survey instrument. Similar to Zailani et al. (2012), this study uses a five-point Likert scale ranging from 1 = "low" to $5=$ "high" in the survey instrument to quantify the existence of each measure. The questionnaire was double-translated from English to Thai and then back to English before being sent to prospective respondents. This was done to ensure that the content was consistent with the original version. The process was facilitated by the research team which consisted of a native Thai speaker.

To assess the coercive mechanisms that force firms to adopt GSCM initiatives, items that reflect legislation, regulation, and customer pressures, both newly constructed and adapted from Carter and Carter (1998), Carter and Ellram (1998), and Darnall (2006) were used. Zailani et al. (2012) introduced some new items to assess green supply chain practices. Eco-design is the 
environmentally conscious design of a product and its packaging to reduce adverse environmental effects throughout its entire life. The seven measured items were adapted from Sarkis (1998) and Zhu et al. (2007). These items were grouped into product related eco-design (three items) and packaging-related eco-design (four items).

The fifteen GSCM performance items were grouped into three broad groupsenvironmental (5 items), economic (4 items), and intangible (6 items) performance. Specific items come from Zhu et al (2007) and Rao (2002). Environmental performance measures the actual impacts of green supply chain initiatives, such as compliance with environmental standards, reduced air emissions, decreased resource consumption, and lower consumption of hazardous materials. Economic performance measures the general improvement in profitability, and reduction in production and material costs. Intangible performance measures the firm's performance in customer satisfaction, loyalty, product and the firm's image. Respondents indicated the performance outcomes on a five-point Likert scale ( 1 = "low," $5=$ "high"), based on the achievements in the past three years as a result of their GSCM initiatives.

\subsection{Sampling Procedure}

In order to ensure that GSCM initiatives had been adopted and implemented at the firm level by respondent organizations, the sampled population was limited to companies who had received ISO 14001 Environmental Management System (EMS) certification in Thailand. The list of these companies was obtained from Thai Industrial Standards Institute (TISI) (available at www.tisi.co.th). Previous studies show that experience in implementing ISO 14001 EMS scheme leads companies to implement green supply chain initiatives (Darnall et al.; 2008; Zhu et al.; 2008). Data was collected from the sample companies by sending the survey instrument to their EMS project management department and specifically, the Environmental Management Representative (EMR).

The instrument was pre-tested by experts in the implementation of GSCM in Thailand. These experts were five ISO 14001 assessors, six EMS consultants, and three academics with research interests in this area. Thereafter, a one-day round table meeting was conducted among the experts to validate all green supply chain initiatives indicated in the instrument and to confirm that the survey was relevant within the context of Thai industry. The final version of the survey instrument was sent to 502 companies listed in the TISI database in October 2011. One 
hundred and ninety (190) valid responses were returned indicating a 37.85\% response rate. Table 1 shows the respondents' profile.

\section{Insert Table 1}

\subsection{Non-response bias}

To test for non-response bias, the responses of early and late waves of returned surveys were compared based on the assumption that the opinions of late respondents are representative of the opinions of the theoretical non-respondents (Rogelberg and Stanton, 2007). The result of t-tests yielded no statistically significant differences between early-wave and late-wave groups, suggesting that non-response bias was not a problem.

\section{Results}

\subsection{Factor analysis and descriptive statistical analysis}

Table 2 shows results from the study. The internal consistency of the constructs was verified by using Cronbach's $\alpha$ and the results indicate that all the values are above 0.7 and this confirms that the constructs are acceptable (Cronbach, 1951). The indicators for the Green Purchasing construct explain $63.74 \%$ of the total variance in the data. The values for the other constructs are as follows: Product-Related Eco-Design (66.17\%); Packaging-Related EcoDesign (65.55\%); Reverse Logistics (64.30\%); Legislation \& Regulation (70.35\%); Environmental Performance (71.91\%); Economic Performance (75.22\%), and Intangible Performance (75.02\%) respectively. Factor loadings for all indicators are above 0.7 with the exception of B3 (ensure purchased materials contain green attributes) which had a factor loading of 0.697 .

A Kaiser-Meyer-Olkin Measure of Sampling Adequacy (KMO) value close to 1 indicates the sum of partial correlations is relatively compact, and factor analysis should yield distinct and reliable factors. Kaiser (1974) recommends KMO values of greater than .50 as acceptable. Table 2 shows that KMO values for all the eight constructs are higher than .50 , hence suggesting that 
factor analysis is appropriate for the data. Bartlett's Sphericity Test checks the null hypothesis that the correlation matrix is an identity matrix (i.e., all correlation coefficients are zero). The Bartlett's tests for all eight constructs reject the null hypothesis at $\alpha=5 \%$ to reaffirm that factor analysis is appropriate for the data.

Insert Table 2

Table 2 also shows the means for each of the constructs' components. With respect to the practices, it is clear that, on average, the Reverse Logistics construct contains the weakest practices followed by the Product-Related Eco-Design construct. The strongest practices are found in the Legislation \& Regulation construct, followed by Packaging-Related Eco-Design practices and finally by Green Purchasing practices. The suggestion, therefore, is that Thai Manufacturers pay greatest attention to and are driven primarily by legislation, regulation and the need to reflect green practices in the design of packaging material. In contrast there is much less focus on reverse logistics, implying that collecting and ensuring recycling of used products or packaging is not seen as much of a priority in contrast to other practices. Similarly, the manufacture of products that use recyclable contents that are themselves recyclable or reusable (Product-Related Eco-Design) is not as highly practiced when compared to most other green supply chain practices.

With respect to the performance constructs, all three constructs show relatively high levels of attainment although, on average, economic performance was slightly weaker than the other two constructs. The implication is that many that manufacturers are attaining a positive image of their organizations and products in the perceptions of employees, suppliers and customers while simultaneously, reducing their consumption and air pollution and also complying with environmental standards.

\subsection{Multivariate Linear Regression Model}

A multivariate general linear regression model was used to test the study's hypotheses. The first sets of hypotheses examined whether business strategy has an impact on firm performance as indicated in $\mathrm{H}_{1}$ to $\mathrm{H}_{6}$. The results show that a low-cost strategy has negative relationships with 
all three dimensions of performance but none of these relationships are statistically significant. As a result of these relationships not being statistically significant, the research failed to support $\mathrm{H}_{1}$ to $\mathrm{H}_{3}$. In contrast, the results indicate that a quality and time-based strategy is positively related to environmental performance $\left(\mathrm{H}_{4}\right)$, economic performance $\left(\mathrm{H}_{5}\right)$, and intangible performance $\left(\mathrm{H}_{6}\right)$. Therefore, these three hypotheses are supported

The second set of hypotheses $\left(\mathrm{H}_{7}\right.$ to $\left.\mathrm{H}_{21}\right)$ examined the relationships between green supply chain practices and the three dimensions of performance. The results from table 3 show that environmental performance is positively related to green purchasing practices $(\beta=.169)$ as well as legislation and regulation $\left(\beta=.211\right.$ ). Consequently, the findings support $\mathrm{H}_{7}$ and $\mathrm{H}_{11} \cdot \mathrm{H}_{12}$ to $\mathrm{H}_{16}$ examined the relationships between green supply chain practices and economic performance and the results suggest that economic performance is positively related to packaging-related ecodesign practices $(\beta=.170)$ as well as legislation and regulation $(\beta=.162)$. Consequently, the findings support $\mathrm{H}_{14}$ and $\mathrm{H}_{16}$. $\mathrm{H}_{17}$ to $\mathrm{H}_{21}$ examined the relationships between green supply chain practices and intangible performance. The results show that there are positive relationships between product-related eco-design practices $(\beta=150)$, packaging-related eco-design practices $(\beta=.192)$, legislation and regulation $(\beta=.160)$ and intangible performance. Therefore, the findings support $\mathrm{H}_{18}, \mathrm{H}_{19}$, and $\mathrm{H}_{21}$ respectively. All other hypotheses are not supported by the finding from the study. Considering $\mathrm{H}_{11}, \mathrm{H}_{16}$ and $\mathrm{H}_{21}$, it is interesting to note that legislation and regulation are positively related to all dimensions of performance while reverse logistics practices are not significantly associated with any of the dimensions of performance. Table 4 summarizes the final decision on whether the proposed hypotheses are supported or not.

Insert Table 3

Insert Table 4 
5.3 Correlation Analysis of Environmental Performance, Economics Performance, and Intangible Performance

The study also examined whether there are significant relationships between the green supply chain performance dimensions as indicated in previous studies (De Giovanni and Esposito, 2012). As indicated in Table 5, all three dimensions of GSCM performance are related to each other. Environmental performance is significantly correlated to economic performance $($ Pearson Correlation $=0.505)$ and intangible performance $($ Pearson Correlation $=0.705)$ while economic performance is correlated to intangible performance (Pearson Correlation $=0.600$ ). These imply that the performance dimensions of GSCM are highly correlated to each other and that GSCM practices that have an effect on one dimension of performance are likely to have a secondary effect on other dimensions.

\section{Insert Table 5}

\section{Discussion}

The findings from this study clearly show the importance of legislation and regulation to GSCM implementation by Thai manufacturers. The fear of legislation associated with compliance with environmental standards and regulations is clearly the most important driver for these organizations. The authors believe that these are defensive and reactionary drivers of practice and performance. The fact that the legislative and regulatory drivers are the only practices associated with all three dimensions of performance further confirm their levels of importance and the perceptive priority in which they are held by Thai manufacturers. In contrast, the level of adoption of reverse logistics is relatively low and it is not significantly associated with any of the dimensions of performance. There may indeed be many varied reasons why the adoption of reverse logistics is low. For example, manufacturers may believe that the cost of putting in place a reverse logistics infrastructure is prohibitive compared to the gains that they foresee. It may also be possible that, depending on the product, reverse logistics is seen as 
impractical or it may well be that the culture of recycling is not deeply entrenched in Thai society. Thai manufacturers have either failed to recognize the role that recycling can play in improving their performance or have decided to ignore it in favor of other green supply chain practices. A study by Lau and Wang (2009), suggested that reverse logistics adoption in the Chinese electronics industry suffer from lack of enforceable laws, prohibitive high cost of investment and low public awareness of environmental protection. This study would suggest that these factors may also be applicable in Thailand. In particular, the high priority given to legislation and regulation in contrast to reverse logistics and product related eco-design would suggest that there are no regulations to motivate adoption of the latter two. It would also suggest that a reactive approach to green supply chain practices is more dominant than a proactive approach.

Previous studies have found a link between green supply chain practices and financial performance and it has also been suggested that the processes that reduce waste and cut costs can not only improve financial performance but can also improve environmental performance (Curkovic et al., 2000; Wu and Pagell, 2011). It has also been suggested that economic performance is the primary priority for manufacturers in developing countries (Zhu and Sarkis, 2007). However, the fact that Thai manufacturers only positively associate packaging related eco-design and legislation and regulations with economic performance suggests a failure to understand the interlinked nature of green supply chain practices and how practices such as product-related eco-design (e.g. using recycled materials, ensuring products are recyclable) and reverse logistics can not only impact environmental and intangible performance, but can also impact economic performance. This interlinked nature was also confirmed in the paper by Kumar et al (2012). Furthermore, there is a disconnect between the high levels of attainment in intangible performance and the relatively high levels of adoption on green purchasing and it appears that Thai manufacturers have not recognized or fully exploited the positive impact that green purchasing practices can have on their products and their corporate image.

The study also found significant positive relationships between a quality and time-based strategy and all three dimensions of performance but no significant relationships were found between a low cost strategy and any of the dimensions of performance. The indication is that organizations that choose a low-cost strategy are unlikely to invest in the adoption of green supply chain practices as a route to improving performance. Clearly, putting in place the 
infrastructure to implement green practices would require resources that may not be available to a low-cost organization or that may be reflected in product pricing and thereby negating the lowcost strategy. On the other hand, organizations that have a quality and time-based strategy are much more likely to link green supply chain practices with their strategy. It can be argued, for example, that producing products or using packaging that is recycled/recyclable and that avoids hazardous material requires a certain level of inherent quality development and time-focused processes and infrastructure to facilitate the logistics of recycling.

\section{Conclusions and Managerial Implications}

This study has examined pro-active and re-active practices in implementing green supply chain and its association with performance among Thai manufacturers. It has found that legislation and regulation is regarded as a priority and is a key driver of environmental, economic and intangible performance while reverse logistics has relatively low adoption levels and was not significantly linked with any of the dimensions of performance. The study has also found that manufacturers that pursue a low cost strategy are less likely to adopt the green practices that will lead to a positive association with the three dimensions of performance examined in this study. Conversely, organizations that adopt a quality and time-based strategy are more likely to invest in green supply chain practices that will lead to a significant positive association with the three dimensions of performance. The study has also argued that Thai manufacturers appear to have failed to understand the potential link between some green supply chain practices and some dimensions of performance. It can therefore be suggested that if this link is properly understood and prioritized, the manufacturers may place more emphasis on pro-active green supply chain practices (as opposed to reactive practices driven by legislation and regulation) and thereby improve their performance levels even more. There are clearly developmental issues still to be considered in the Thai manufacturing industry within the context of green supply chain management.

This study has significant managerial implications for Thai manufacturing industry and potentially other developing countries. First, Thai manufacturers need to understand the potential positive impact that green supply chain practices can have on different dimensions of performance and consequently, be more pro-active in their adoption of such practices. Secondly, the country's authorities need to recognize the impact of legislation and regulation on the actions 
of manufacturers and consider how this can be utilized to further enhance green supply chain practices e.g. recycling and reuse of products and packaging. Thirdly, organizations need to be aware that pursuing a low cost strategy may impact on their ability to invest in green supply chain practices and this not only precludes them from gaining the associated benefits but may leave them vulnerable and exposed to future legislation and regulations.

Academically, there is a need to understand the missing links between some of the GSCM practices and some of the dimensions of performance considered in this study. There is also a need to examine infrastructure and strategies for reverse logistics in developing countries such as Thailand.

\section{Acknowledgement}

This work was supported by the Higher Education Research Promotion and National Research University Project of Thailand, Office of Higher Education Commission. The authors would like to thank the Faculty of Engineering, Thammasat University for supporting this research project.

\section{References}

Anderson, S.W., Daly J.D. and Johnson M.F. (1999), "Why firms seek ISO 9000 certification: regulatory compliance or competitive Advantage?", Production and Operations Management, Vol. 8 No. 1, pp. 28-43.

Arlbjørn J.S., and Lu“thje T. (2012),'Global operations and their interaction with supply chain performance”, Industrial Management \& Data Systems, Vol. 112 No. 7, pp. 1044-1064

Azevedo, S., Carvalho, H., and Machado, V. (2011), "The influence of green practices on supply chain performance: A case study", Transportation Research Part E, Vol. 47, pp. 850-871.

Boyer, K. and Lewis, M. (2002), "Competitive priorities: investigating the need for trade-offs in operations strategy", Production and Operations Management, Vol. 11 No. 1, pp. 9-20.

Braunscheidel M.J., Hamister J.W., Suresh N.C., Star H. (2011), “An institutional theory perspective on Six Sigma adoption”, International Journal of Operations \& Production Management, Vol. 31 No. 4, pp. 423-451. 
Buyukozkan, G. and Cifci, G. (2012), "Evaluation of green supply chain management practices: a fuzzy ANP approach”, Production Planning and Control, Vol. 23 No. 6, pp. 405-418.

Carter, C.R. and Carter, J.R. (1998), "Inter-organizational determinants of environmental purchasing: initial evidence from the consumer products industries", Decision Sciences, Vol. 29 No. 3, pp. 659-684.

Carter, C.R. and Ellram, L.M. (1998), "Reverse logistics: a review of the literature and framework for future investigation”, Journal of Business Logistics, Vol. 19 No. 1, pp. 85102.

Carter J.C., Smeltzer L., and Narasimhan R. (2000), "Human resource management within purchasing management: Its relationship to total quality management success", The Journal of Supply Chain Management, Vol. 36 No. 2, pp. 52-62.

Chen, Y. and Sheu, J-B. (2009), "Environmental regulation pricing strategies for green supply chain management", Transportation Research Part E, Vol. 45, pp. 667-677.

Chung, C-J.and Wee, H-M. (2011), "Short life-cycle deteriorating product remanufacturing in a green supply chain inventory control system", International Journal of Production Economics, Vol. 129, No.1, pp. 195-203.

Cronbach, L.J. (1951), “Coefficient alpha and the internal structure of tests”, Psychometrika, Vol. 16, pp. 297-334.

Curkovic, S., Melnyk, S., Handfield, R., Calantone, R. (2000), "Investigating the linkage between total quality management and environmentally responsible manufacturing", IEEE Transactions on Engineering Management, Vol. 47 No. 4, pp. 444- 464.

Darnall, N. (2006), "Why firms mandate ISO 14001 certification”, Business \& Society, Vol. 45 No. 3, pp. 354-381.

Das, K. (2012), "Integrating reverse logistics into the strategic planning of a supply chain", International Journal of Production Research, Vol. 50, No. 5, pp. 1438-1456.

De Giovanni, P. and Esposito Vinzi, V. (2012), "Covariance versus component-based estimations of performance in green supply chain management", International Journal of Production Economics, Vol. 135, No.2, pp. 907-916. 
Delmas M., and Toffel, M.W. (2004), "Environmental management practices: an institutional framework", Business Strategy and the Environment, Vol. 13, pp. 209-222.

Diabat, A. and Govindan, K. (2011), "An analysis of the drivers affecting the implementation of green supply chain management", Resources, Conservation and Recycling, Vol. 55, pp. 659667.

Eltayeb, T., Zailani, S. and Ramayah, T. (2011), "Green supply chain initiatives among certified companies in Malaysia and environmental sustainability: Investigating the outcomes", Resources, Conservation and Recycling, Vol. 55, pp. 495-506.

Ferdows, K. (1997), Making the most of foreign factories, Harvard Business Review, MarchApril, pp. 73-88.

Ferdows, K. and De Meyer, A. (1990), "Lasting improvements in manufacturing performance: in search of a new theory", Journal of Operations Management, Vol. 9 No. 2, pp. 168-183.

Field, J. and Sroufe, R. (2007), "The use of recycled materials in manufacturing: implications for supply chain management and operations strategy", International Journal of Production Research, Vol. 45 No. 18/19, pp. 4439 - 4463.

Green, K., Zelbst, P., Meacham, J. and Bhadauria, V. (2012), "Green Supply Chain Management Practices: Impact on performance", Supply Chain Management-An International Journal, Vol. 17 No.3, pp. 1-44.

Heras-Saizarbitoria, I., Landín, G. and Molina-Azorín, J. (2011), "Do drivers matter for the benefits of ISO 14001?", International Journal of Operations \& Production Management, Vol. 31 No. 2, pp. 192-216.

Hitchcock, T. (2012), "Low carbon and green supply chains: the legal drivers and commercial pressures", Supply Chain Management-An International Journal, Vol. 17 No. 1, pp. 98-101.

Huang, Y-C., Wu, Y- C. and Rahman, S. (2012), "The task environment, resource commitment and reverse logistics performance: evidence from the Taiwanese high-tech sector", Production Planning and Control, Vol. 23, No. 10-11, pp. 851-863

Kaiser, H. F. (1974), “An index of factoral simplicity”, Psychometnka, Vol. 39, pp. 31-36. 
Kathuria, R. (2000), “Competitive priorities and managerial performance: a taxonomy of small manufacturers”, Journal of Operations Management, Vol. 18 No. 6, pp. 627-641.

Kenneth W. G., Jr, Zelbst P.J., Bhadauria V. S., and Meacham J. (2012), "Do environmental collaboration and monitoring enhance organizational performance?", Industrial Management \& Data Systems, Vol. 112 No. 2, pp. 186-205

Ketokivi, M.A. and Schroeder, R.G. (2004), "Strategic, structural contingency and institutional explanations in the adoption of innovative manufacturing practices”, Journal of Operations Management, Vol. 22 No.1, pp. 63-89.

Koh, S.C.L., Gunasekaran, A. and Tseng, C.S. (2012), "Cross-tier ripple and indirect effects of directives WEEE and RoHS on greening a supply chain”, International Journal of Production Economics, Vol. 140.No.1, pp.305-317.

Kumar, S. and Putnam, V. (2009), "Cradle to cradle: Reverse logistics strategies and opportunities across three industry sector", International Journal of Production Economics, Vol. 115 No. 2, pp. 305-315.

Kumar, S., Teichman, T. and Timpernagel, T. (2012), “A green supply chain is a requirement for Profitability", International Journal of Production Research, Vol. 50, No. 5, pp. 1278-1296.

Lee, S. M., Kim, S.T., and Choi, D. (2012), “Green supply chain management and organizational performance”, Industrial Management \& Data Systems, Vol. 112, No. 8, pp. 1148 - 1180.

Lee K-H and Cheong I-M. (2011),'Measuring a carbon footprint and environmental practice: the case of Hyundai Motors Co. (HMC)”, Industrial Management \& Data Systems, Vol. 111 No. 6, pp. 961-978

Large, R.O. and Thomsen, C.G. (2011), "Drivers of green supply management performance: Evidence from Germany", Journal of Purchasing \& Supply Management, Vol. 17, No. 3, pp. 176-184.

Lau, K. and Wang, Y. (2009), "Reverse logistics in the electronic industry of China: a case study”, Supply Chain Management: An International Journal, Vol. 14 No. 6, pp. 447-465. 
Lee, S-Y. (2008), "Drivers for the participation of small and medium-sized suppliers in green supply chain initiatives", Supply Chain Management: An International Journal, Vol. 13 No. 3, pp. 185-198.

Lin, R-J., Chen, R-H.and Nguyen, T-H. (2011), “Green supply chain management performance in automobile manufacturing industry under uncertainty", Procedia-Social and Behavioral Sciences, Vol. 25, pp. 233-245.

Lu, L., Wu, C. and Kuo, T-C. (2007), "Environmental principles applicable to green supplier evaluation by using multi-objective decision analysis", International Journal of Production Research, Vol. 45 No. 18/19, pp. 4317-4331.

Min, H. and Galle, W. (2001), "Green purchasing practices of US firms", International Journal of Operations and Production Management, Vol. 21 No. 9, pp. 1222-1238.

Murphy, P. and Poist, R. (2003), “Green perspectives and practices: a 'comparative logistics' study”, Supply Chain Management: An International Journal, Vol. 8 No. 2, pp. 122-131.

Narasimhan R., and Carter J.R. (1998), "Environmental supply chain management", Research Monograph, Center for Advanced Purchasing Studies, Tempe, AZ.

Olorunniwo, F. and Li, X. (2010), "Information sharing and collaboration practices in reverse logistics”, Supply Chain Management-An International Journal, Vol. 15 No. 6, pp. 454-462.

Phusavat, K. and Kanchana, R. (2007), "Competitive priorities of manufacturing firms in Thailand", Industrial Management \& Data Systems, Vol. 107, No. 7, pp. 979-996.

Rao, P. (2002), "Greening the supply chain: a new initiative in South East Asia”, International Journal of Operations and Production Management, Vol. 22 No. 6, pp. 632-655.

Rao, P. and Holt, D. (2005), "Do green supply chains lead to competitiveness and economic performance?", International Journal of Operations and Production Management, Vol. 25 No. 9, pp. 898-916.

Rivera, J. (2004), "Institutional pressures and voluntary environmental behavior in developing countries: evidence from the Costa Rican hotel industry", Society and Natural Resources, Vol. 17, pp. 779-797. 
Rogelberg, S.G. and Stanton, J.M. (2007), "Understanding and dealing with organizational survey nonresponse”, Organizational Research Methods, Vol. 10, pp. 195-209.

Sarkis, J. (1998), "Evaluating environmentally conscious business practices”, European Journal of Operational Research, Vol. 107, No.1, pp.159-174.

Sarkis, J. (2012), "A boundaries and flows perspective of green supply chain management", Supply Chain Management: An International Journal, Vol. 17, No. 2, pp. 202-216.

Sarkis J., Zhu Q., Lai K.H. (2011), “An organizational theoretic review of green supply chain management literature", International Journal of Production Economics, Vol. 130, No.1, pp. $1-15$.

Sheu, J-B. (2011), "Bargaining framework for competitive green supply chains under governmental financial intervention”, Transportation Research Part E, Vol. 47, pp. 573-592.

Srivastava, K. S. (2007), “Green supply-chain management: a state-of-the-art literature review”, International Journal of Management Reviews, Vol. 9, No. 1, pp. 53-80.

Testa, F. and Iraldo, F. (2010), "Shadows and lights of GSCM (Green Supply Chain Management): determinants and effects of these practices based on a multinational study", Journal of Cleaner Production, Vol. 18, No. 10-11, pp. 953-962.

Teuteberg, D. and Wittstruck, F. (2012), "Understanding the Success Factors of Sustainable Supply Chain Management: Empirical Evidence from the Electrics and Electronics Industry", Corporate Social Responsibility and Environmental Management, Vol. 19 No. 3, pp. 141-158.

Vachon, C. (2007), "Green supply chain practices and the selection of environmental technologies", International Journal of Production Research, Vol. 45 No. 18/19, pp. 43574379.

Walker, H., Di Sisto, L. and McBain, D. (2008), "Drivers and barriers to environmental supply chain management practices: Lessons from the private and public sectors", Journal of Purchasing and Supply Management, Vol. 14, No.1, pp. 69-85. 
Ward, P. and Duray, R. (2000), "Manufacturing strategy in context: environment, competitive strategy and manufacturing strategy", Journal of Operations Management, Vol. 18 No. 2, 123-138.

Wu, K-J., Tseng, M-L, and Vy, T. (2011), "Evaluation the drivers of green supply chain management practices in uncertainty", Procedia - Social and Behavioral Sciences, Vol. 25, pp. 384-397.

Wu, Z. and Pagell, M. (2011), "Balancing priorities: Decision-making in sustainable supply chain management”, Journal of Operations Management, Vol. 29, No. 6, pp. 577-590.

Xie, Y. and Breen, L. (2012), "Greening community pharmaceutical supply chain in UK: a cross boundary approach", Supply Chain Management: An International Journal, Vol. 17 No. 1, pp. 40-53.

Zailani, S.H.M., Eltayeb, T.K., Hsu, C.C., and Tan, K.C. (2012), "The impact of external institutional drivers and internal strategy on environmental performance", International Journal of Operations \& Production Management, Vol. 32 No. 6, pp. 721-745.

Zhu, Q. and Sarkis, J. (2004), "Relationships between operational practices and performance among early adopters of green supply chain management practices in Chinese manufacturing companies", Journal of Operations Management, Vol. 22, No. 3, pp. 265289.

Zhu, Q. and Sarkis, J. (2007), “The moderating effects of institutional pressures on emergent green supply chain practices and performance", International Journal of Production Research, Vol. 45 No. 18/19, pp. 4333-4355.

Zhu, Q., Sarkis, J. \& Lai, K. (2007), “Green supply chain management: pressures, practices and performance within the Chinese automobile industry", Journal of Cleaner Production, Vol. 15 No.11/12, pp. 1041-1052.

Zhu, Q., Sarkis, J. and Geng, Y. (2005), "Green supply chain management in China: pressures, practices and performance", International Journal of Operations and Production Management, Vol. 25 No. 5, pp. 449-468. 
Zhu, Q., Sarkis, J. and Lai, K-H. (2008), "Confirmation of a measurement model for green supply chain management practices implementation", International Journal of Production Economics, Vol. 111 No. 2, pp. 261-273.

Zhu, Q., Sarkis, J. and Lai, K-H. (2012), "Examining the effects of green supply chain management practices and their mediations on performance improvements", International Journal of Production Research, Vol. 50, No. 5, pp. 1377-1394.

Zhu Q., Geng Y., Fujita T., and Hashimoto S. (2010), "Green supply chain management in leading manufacturers: Case studies in Japanese large companies", Management Research Review, Vol. 33 No.4, pp. 380-392. 